\title{
A Guerra da Coréia vista após sessenta anos de Armistício (1953-2013) ${ }^{1}$
}

The Korean War analyzed sixty years after the Armistice (1953-2013)

Elói Martins Senhoras²

Rita de Cássia de Oliveira Ferreira ${ }^{3}$

\section{RESUMO}

O boletim discute a evolução geoestratégica da Guerra da Coréia e sua repercussão nas relações internacionais a fim de fornecer subsídios analíticos para a compreensão dos tensionamentos pendulares de longa duração existentes na península coreana até o ano de 2013, quando o Armistício é declarado nulo pela Coréia do Norte.

Palavras-chave: Armistício; Guerra da Coréia; Península da Coréia

\begin{abstract}
The report discusses the evolution of the geostrategic Korean War and its impact on international relations in order to provide support for the analytical understanding of the tensions commuting long-standing on the Korean peninsula by the year 2013, when the Armistice is declared void by the Korea North.
\end{abstract}

Key-words: Armistice, Korean War, Korean Peninsula

A Guerra da Coréia, que aconteceu entre os anos de 1950 e 1953, teve sua origem em um contexto pós II Grande Guerra Mundial, de bipolarização mundial, quando os Estados Unidos e a União Soviética - ex-aliados que tinham lutado juntos na II Guerra Mundial - entram em conflito para controlar os territórios da península da Coréia.

Com o fim da II Guerra Mundial, a península da Coréia, que fora protetorado japonês desde 1905, encontrou-se como foco inicial de uma potencial III Guerra

\footnotetext{
${ }^{1}$ Artigo recebido em 04 de setembro de 2013 e aprovado para publicação em 11 de setembro de 2013.

${ }^{2}$ Economista e cientista político, especialista, mestre, doutor e pós-doutorando em Ciências Jurídicas. É professor universitário em cursos de graduação e pós-graduação da Universidade Federal de Roraima (UFRR), Boa Vista, Brasil. Email para contato: eloisenhoras@gmail.com.

3 Graduanda em Relações Internacionais e pesquisadora, bolsista de iniciação científica do Núcleo Amazônico de Pesquisa em Relações Internacionais (NAPRI) pela Universidade Federal de Roraima, Boa Vista, Brasil. Email para contato: rita_oferreira@hotmail.com.
} 
Mundial, fato que ficara conhecido como Guerra Fria, uma vez que as tropas japonesas no controle da Coréia foram rendidas, tanto pela União Soviética, que ocupava o norte da Coréia, quanto pelos Estados Unidos, que ocupavam o Sul.

Em um primeiro momento, no ano de 1945, o acordo entre os governos de Moscou e Washington ocorrido na Conferência de Potsdam oficializou o "Paralelo 38", que cruzava o país, como linha responsável por dividir a península da Coréia em duas zonas: a do norte, ocupada por soviéticos, e a do sul, sob controle americano.

Desde o início, houve um processo de tentativa para reunificação pacífica entre os territórios da península da Coréia, porém que nunca foi adiante, haja vista as agendas distintas de proposições do Norte, ao propor aproximação política na qual se procuraria convergir as políticas externa e de defesa vis-à-vis às do Sul, ao defender uma aproximação "funcionalista" alicerçada na promoção das trocas inter-coreanas para estabelecer confiança mútua.

Em um segundo momento, no ano de 1948, a proclamação de independência da República Democrática Popular da Coréia (Coréia do Norte) cindiu politicamente a península, dando origem a dois países distintos, respectivamente, com um novo Estado Nacional socialista ao norte vis-à-vis ao tradicional Estado Nacional capitalista, a República da Coréia (Coréia do Sul).

Meio a levantes populares, os líderes nacionalistas coreanos Syngman Rhee, do território Sul, e Kim Il-Sung, do Norte, propunham um modelo para reunificar a Coréia de maneira que obedecesse, exclusivamente, a um dos dois tipos de sistemas políticos, motivo pelo qual, sem êxito, ambos os governos desistiram da tentativa de convenção e iniciaram reivindicações pela competência sobre a totalidade do território coreano, gerando grande tensão nas áreas de fronteira, na tentativa de conquistar simpatizantes das suas políticas.

Em um terceiro momento, entre os anos de 1950 e 1953, trava-se um conflito fratricida para delimitação das fronteiras com avanços e recuos e que traz graves consequências para ambos os lados, haja vista que somente após 3 milhões de pessoas terem sido mortas, um armistício foi assinado, embora nunca tenha surgido assinatura de acordo de paz, pois nenhuma das Coreias reconhece a outra como país. 


\section{Mapa 1 - Evolução da Guerra da Coréia}

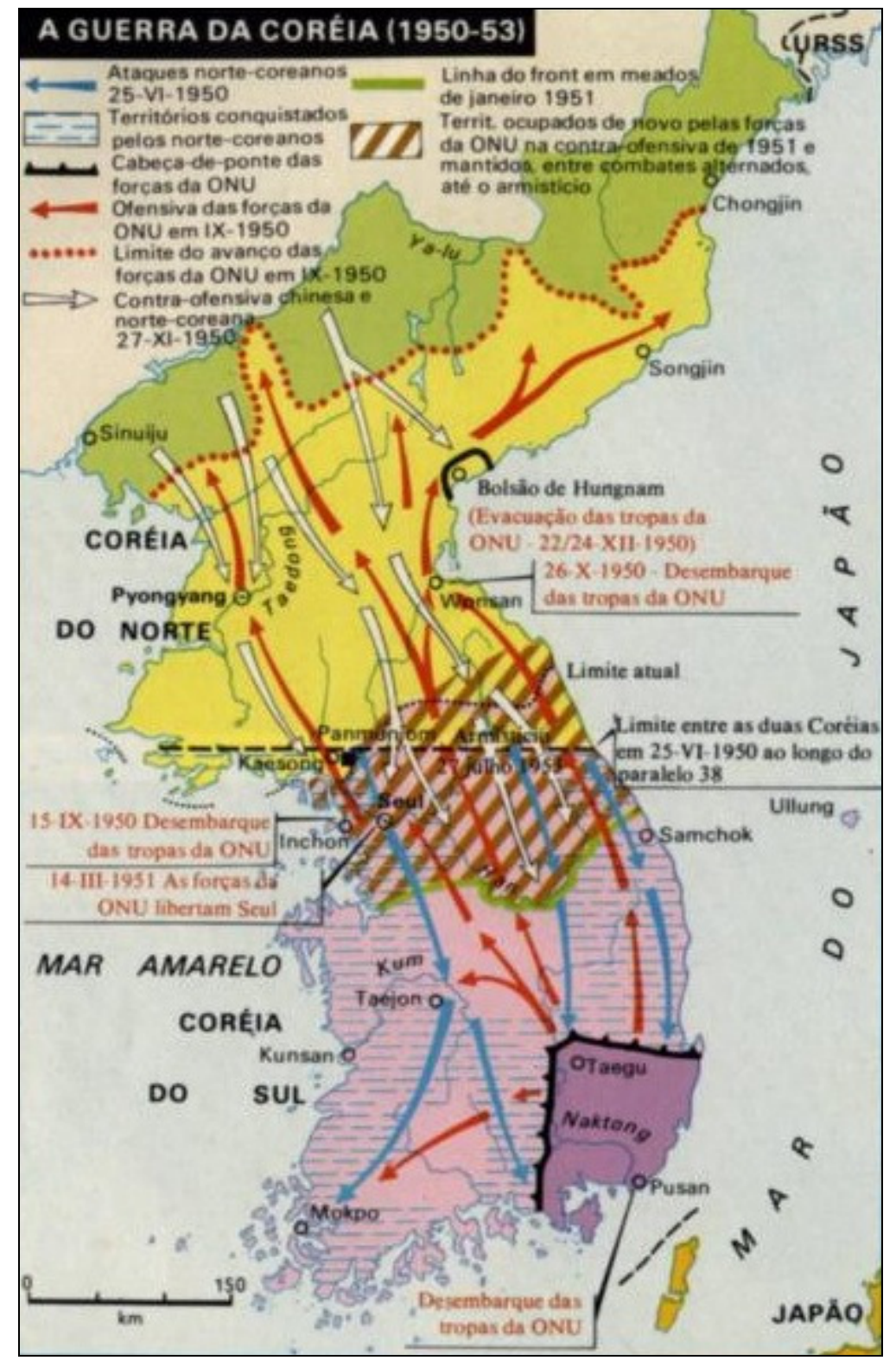

Fonte: NEC (2009).

A compreensão do desenvolvimento da Guerra da Coréia entre 25 de Junho de 1950 e 27 de Julho de 1953 é fragmentada diante dos argumentos expostos pelas partes, motivo pelo qual surgiram pelo menos duas vertentes de interpretação histórica sobre o estopim da crise que evoluiu para um conflito com repercussão mundial diante dos players internacionais envolvidos (MARTINS, 2011).

Segundo a perspectiva da análise internacional, identifica-se uma visão 
tradicionalista que fundamenta o ataque norte-coreano em um suposto acordo secreto entre os líderes Joseph Stalin (1878-1953), Kim Il-sung (1912-1994) e Mao Tse-tung (1893-1976) vis-à-vis a uma visão revisionista, na qual a guerra seria o resultado de uma sequencial provocação militar da Coréia do Sul sob a ordem do general Douglas MacArthur (1880-1964).

Segundo a perspectiva da análise nacional, a guerra da Coréia fundamentava-se em um estado de arrefecimento das tensões em ambas as zonas do território cindido pelo paralelo 38, uma vez que a crescente polarização de clivagens político-ideológicas entre os dirigentes políticos e as classes sociais coreanas acabaram exacerbando as divergências e fechando os tradicionais canais de negociação, o que repercutiu no surgimento de uma guerra civil.

A despeito das diferenças interpretativas sobre a origem da Guerra, observa-se que a contextualização de justificativas nacionais e internacionais acaba por reforçar uma complementaridade analítica sobre o fenômeno, demonstrando a magnificação do grau de complexidade da península coreana, a qual se tornou o primeiro teatro de operações de um conflito bipolar que viria a ser conhecido por Guerra Fria.

Existe um claro efeito cascata na guerra da Coréia que é oriundo de uma dinâmica propagação complexa de polarizações, tanto endógenas, quanto exógenas, na qual os conflitos territoriais manifestam-se por uma exacerbação conflitiva, que é, não apenas local, mas também refrativa a uma crescente interferência de outros países mobilizados pela projeção de poder internacional frente às diferenças políticoideológicas existentes.

De um lado, com o intenso envolvimento da União Soviética na militarização da Coréia do Norte, Josef Stalin aprovou, em 1950, o envio de tropas norte-coreanas, as quais eram compostas por soldados que lutaram na Revolução Chinesa, para uma ofensiva contra a Coréia do Sul, que atravessou o Paralelo 38 e chegou a Seul, forçando os sul-coreanos a recuar para o Sul.

De outro lado, como contra-resposta à invasão de Seul, o presidente sulcoreano Rhee, ordenou não somente a evacuação da capital, mas também implementou uma política de eliminação de milhares de indivíduos supostamente identificados como simpatizantes do comunismo, política esta que seria coadunada pela declaração de 
guerra à Coréia do Norte pelo governo estadunidense.

Frente à evolução dos conflitos, o Conselho de Segurança das Nações Unidas aprovou as resoluções 82 e 83, as quais deliberavam, respectivamente, a reprovação da invasão da Coréia do Norte pela Coréia do Sul, e a autorização para intervenção militar de tropas da ONU para por fim ao conflito, o que repercutiu na entrada da China no conflito, obrigando as tropas da ONU a recuar.

Em um movimento de contra-ofensiva, comandado pelo general estadunidense Mac Arthur, observou-se uma rápida dinâmica de reconquista dos territórios sulcoreanos e de significativo avanço sobre a maior parte do território norte-coreano, o que repercutiu em uma inversão do contexto inicial da guerra e na entrada da China, conduzindo o conflito aos territórios fronteiriços do paralelo 38.

Durante os anos que se seguiram, desde o início das hostilidades e que vão até 1953, observa-se que o teatro de guerra restringiu-se a uma zona fronteiriça em que aconteceram movimentos de pouco impacto, notadamente territórios próximos ao paralelo 38, desde a libertação de Seul pelas tropas da ONU em 1951, período que registrou tentativas desta Organização multilateral para suspender as hostilidades por meio de convenções de paz.

Com a assinatura do armistício em 1953, surgiram cinco mecanismos para manter a trégua entre as Coréias: a) Linha de Demarcação Militar (MDL), separando oficialmente os países; b) Zona Desmilitarizada (DMZ), que se estende na fronteira com uma extensão de 250 km e uma largura de 2 km em cada país; c) Comissão de Armistício Militar (MAC), responsável por investigar e resolver violações no armistício; d) Área de Segurança Conjunta (JSA), localizada dentro da DMZ, inclui a sede do MAC e Panmunjom, e, finalmente, d) Comissão de Supervisão por Nações Neutras (NNSC), responsável por assegurar o cumprimento do armistício (PARK, 2009).

Ainda que a assinatura do armistício tenha acontecido somente em 1953, o que permitiu interromper as batalhas, quando foram fixadas as fronteiras entre as Coréias, a sua repercussão no custo da divisão vem até os dias de hoje, já que os países se desenvolveram economicamente com padrões altamente distintos e assimétricos, enquanto, politicamente, o conflito nunca terminou, mas apenas fora interrompido por tempo indefinido. 
O gap de desenvolvimento nos distintos modelos coreanos foi se ampliando simultaneamente a uma série de tentativas de acordos de paz e de projetos de cooperação, o que repercutiu na consolidação de um sistemático movimento pendular nas relações entre ambos países após 60 anos de armistício, que passa tanto por melhoras, quanto por deteriorações, haja vista o posicionamento oscilatório da Coréia do Norte para barganhar e eventualmente atuar como free-rider nas relações internacionais.

Tal movimento pendular, que vem desde o armistício, embora propicie temas de convergência, como a diplomacia esportiva, quando ambos os países participam juntos em eventos esportivos, utilizando uma bandeira de unificação da península, também tem repercutido, mais frequentemente, em desentendimentos e atos de agressão devido ao fim da Guerra Fria e do apoio da União Soviética à Coréia do Norte (MERKEL, 2008).

Em um contexto de fim da Guerra Fria, por um lado, enquanto o vitorioso bloco ocidental-capitalista, liderado pelos Estados Unidos, não se aproxima da Coréia do Norte, esperando um natural desmonte do regime socialista, tal como registrado na Europa, por outro lado, o regime socialista-ditatorial norte-coreano procura fugir do ostracismo ao se abrir para a Coréia do Sul na década de 1990 e, ao se projetar com algum grau de negociação no tabuleiro multilateral das relações internacionais, mesmo que de maneira autônoma por meio de uma política de barganha nuclear na década de 2000.

Na década de 1990, observa-se parcial adesão da Coréia do Norte a uma sunshine police sul-coreana, que findava promover a reunificação da península, gradualmente, por mecanismos de soft power, na dimensão sociocultural, com a promoção de reencontros de famílias separadas e com a diplomacia turística e esportiva; e, principalmente, na dimensão econômica, com o ingresso de empresas sul-coreanas em território norte-coreano que levaram à criação e a formação de três Zonas Econômicas Especiais - ZEEs (KEY-YOUNG, 2006).

$\mathrm{Na}$ década de 2000, frente ao neoconservadorismo estadunidense desde 2001, não por acaso, surge na Coréia do Norte crescente estratégia de polarização, tanto com os regimes multilaterais construídos sob negociação hegemônica dos Estados Unidos, quanto com os regimes regionais na Ásia, haja vista a sua intenção de obter ganhos de 
segurança econômica por meio de barganha com Coréia do Sul, China, Japão e a própria Rússia.

0 endurecimento da retórica norte-coreana propiciada desde o abandono do Tratado de Não-Proliferação Nuclear em 2003 e o primeiro teste de lançamento balístico nuclear em 2006, após dez anos, repercutiu em um contexto de inflexão estrutural em 11 de março de 2013, quando, após novas sanções da Organização das Nações Unidas (ONU) contra as políticas do regime da Coréia do Norte, o novo líder deste país, consolidando-se como terceira geração ditatorial, decretou nulo o acordo de armistício.

Conclui-se com base nessas discussões que o crescente tensionamento na península Coréia desde março de 2013 - engendrado pelo líder norte-coreano, Kim Jongun, ao confirmar o fim do armistício com a Coréia do Sul - corrobora para a compreensão de que existe uma inflexão na longa duração da declaração Norte-Sul de não-agressão que merece atenção, por mais que persista uma recorrente estratégia norte-coreana de chantagem e barganha política a fim de se trazerem ganhos a um país que se encontra isolado por sanções internacionais.

\section{Referências Bibliográficas}

KEY-YOUNG, S. South Korean Engagement Policies and North Korea: Identities, Norms and the Sunshine Policy. New York: Routledge, 2006.

MARTINS, M, A. “As duas Coréias: Zona crítica de tensões internacionais. Zonas de crise na geopolítica mundial”. Janus Anuário (2011 - 2012), vol. 2, 2011. Disponível em: $<$ www.janusonline.pt>. Acessado em 22/05/2013.

MERKEL, U. "The Politics of Sport Diplomacy and Reunification in Divided Korea: One Nation, Two Countries and Three Flags". International Review for the Sociology of Sport, September, vol. 43, n. 3, 2008.

NEC - Núcleo de Estudos Contemporâneos. "Guerra da Coréia". Mapas históricos, 10 de setembro, 2009. Disponível em: <www.historia.uff.br/nec>. Acessado em $30 / 05 / 2013$.

PARK, W. G. "The United Nations Command in Korea: past, present, and future". Korean Journal of Defense Analysis, vol. 21, n. 4, 2009. 